\title{
A Survey of Acquisition of Transferred Negation of English Syntax With Reference to Senior High School TEFL in Mainland China
}

\author{
Liu Fuli $^{1} \&$ Song Shuang ${ }^{1}$ \\ ${ }^{1}$ School of Foreign Languages, Southwest University, Chongqing, China \\ Correspondence: Liu Fuli, School of Foreign Languages, Southwest University, Beibei district, Chongqing, \\ China. Tel: 136-2975-8520. E-mail: frankliu@swu.edu.cn
}

Received: September 25, 2014 Accepted: December 11, 2014 Online Published: January 20, 2015

doi:10.5539/elt.v8n2p55 URL: http://dx.doi.org/10.5539/elt.v8n2p55

\begin{abstract}
This study investigates the learning situation of senior high school students in mainland China about acquisition of transferred negation of English sentence structure. Through translation test and questionnaire investigation, a survey is made about this language learning phenomenon among 173 students. From the study it is found that students mainly have problems with the typical kind of transferred negation sentences, the negation caused by the predicative in the matrix clause, the negation of because-clause, the negation of infinitive structure or the objective complements and so on. The language foundation of English has no direct relation to whether students are familiar with transferred negation structure. There exists a very clear difference between students from different schools for some sentences and students from the same class tend to make mistakes in the same kind of transferred negation sentences. Female students have an advantage over male students in the translation test. Some factors like the habits of Chinese expression have great effects on students' understanding of the structure.
\end{abstract}

Keywords: TEFL, transferred negation, senior high school, China

\section{Introduction}

In English, the phenomenon that a negative word or element moves out of its original position to a new place had existed long before it was definitely defined as "transferred negation" by Quirk et al. (1972). Language learners are liable to make mistakes with these sentences, and this study was carried out to investigate the learning situation of some senior high school students about transferred negation and make some suggestions about the learning and teaching of it.

In English, the transferred negation structure is a more preferable pragmatic strategy so that a native speaker would say "I don't think he is a good teacher" instead of "I think he is not a good teacher." For Chinese learners of English language, they would find it confusing and difficult when they are trying to understand the meaning or to translate the sentence into corresponding Chinese language.

Transferred negation is not a key grammar concept in College Entrance Examination in mainland China so some English teachers even ignore the teaching of this part. But we can not deny its importance in language uses and cross-cultural communication, so this study aims to investigate the learning situation of some senior high school students about transferred negation and make some suggestions about the learning and teaching of this kind of sentence structure.

\section{Literature Review}

"Transferred negation", can also be termed as "negative raising" or "negative transportation" (Quirk et al., 1985, p. 1033). It usually occurs when one of a particular set of mental activity verbs, such like think and suppose, introducing an indirect statement is structurally negated but semantically throws its negation forward to the main verb or adjective in the indirect statement. One of the most common structures of transferred negation is like "I don't think that..." According to Morante and Sporleder (2012), negation is a complex phenomenon that has been studied from many perspectives, including cognition, philosophy, and linguistics. In English, the usual negative formation is as follows: "When we use verbs like think, suppose and believe to introduce a negative idea, we prefer to make the introductory verb negative, not the verb in the subordinate clause." (Foley \& Hall, 2005, p. 89). This special phenomenon attracted the attention of the scholars for a very long time, and one of the earliest formal documents about it appeared in A Grammar of Contemporary English in 1972. According to the 
introduction of this grammar book, transferred negation, particularly common in informal style, is the transfer of the negative from a subordinate clause (generally a that-clause), where semantically it belongs, to the matrix clause (Quirk et al., 1985). For example, the sentence "I believe she won't come tomorrow." could be transformed into "I don't believe she will come tomorrow." and thus the location of negation is moved to another place.

From the perspective of pragmatics, transferred negation is regarded as a result of the adaptation of the grammar to certain social institutions. Bybee (1994) figured out that the necessary condition of the grammaticalization of a structure is that it is used in a high frequency. The preference of uses of the transferred negation leads to a result that the relevant structures are accepted by the society, and developed into established usage. Gradually it becomes a rule, in other words, a grammatical conceptualization.

Brown and Levinson (1987, p. 62) divided "face" into positive face and negative face. The former is "the want of every member that his wants be desirable to at least some others executors", or alternately, "the positive consistent self-image or 'personality' (crucially including the desire that this self-image be appreciated and approved of) claimed by interactants". Negative face was defined as "the want of every "competent adult member' that his actions be unimpeded by others", or "the basic claim to territories, personal preserves, rights to non-distraction--i.e. the freedom of action and freedom from imposition". That is to say, positive face refers to one's self-esteem, while negative face refers to one's freedom to act. The two aspects of face are the basic wants in any social interaction, and so during any social interaction, cooperation is needed among the subjects to maintain each other's faces (Foley, 1997). Negation itself is a face threatening act to some degree for it expresses one's denial and so on, so the speakers need to express it in a more polite way to save the face of each other through the use of strategies such as transferred negation. According to Horn (1978), negative force is weakened when the distance the negative word and its logically (semantically) negated constituent(s) is elongated.

The 66 conversation texts collected by Svartvik and Quirk (1980) showed that the ratio of using transferred negation and "not" is nearly ten to one. Xiong (1988) collected 74 sentences written by native English speakers, and he found that the verbs used in the main clauses were think, suppose and imagine and that most of the sentences used transferred negation. Chen (2005) also did a survey about the problem by analyzing 60 electronic documents which included 30 online chatting documents, 30 oral interview documents with native speakers and 30 articles. The ratio of using negative structure in the main clause or the subordinate clause was calculated and the similar conclusion was obtained as the above studies.

In Chinese context of TEFL, Xiang (1999) put forward that students should be taught how to identify transferred negation because it is a complicated structure. The difficulty lies in the difference between the way of thinking. Students should be taught how to make sure of the focus and scope of the negation when understanding the sentences. It is argued that in traditional grammar teaching, many kinds of transferred negation lack systematic explanations, so it may be a cause for language learners to make mistakes of English sentence structure; and possibly the question could be solved by teaching students of transferred negation from the perspective of functional grammar so as to help learners to have further information about its features of function and cognitive motive (Liu, 2011). Cao (2006) analyzed the causes of the ambiguity of negation in order to propose ways to help students to understand the negation in English better; she proposed that different verbs used in the sentences will probably influence the interpretation selection.

The above studies of transferred negation help understand the acquisition of English syntax, particularly in Chinese context of TEFL.

\section{Research Design}

\subsection{Research Questions}

The initial objective of this study is to get an understanding of the situation of learning English transferred negation in senior high schools in mainland China, which might help improve teaching of this aspect in TEFL. Specifically the following questions will be discussed:

1) Which kind of transferred negation sentences are they familiar with?

2) Will English language foundation of senior high school students influence their acquisition of transferred negation?

3) Is there any clear difference of acquisition of transferred negation between students from different schools?

4) Is there a significant difference of acquisition of transferred negation between male and female students? 


\subsection{Subjects}

The subjects are all senior high school students and they are all in grade two, from High School Affiliated to Southwest University, Jianshan Middle School and Datong Locomotive Middle School. The first two middle schools are in Chongqing municipality, and the last one is in Datong, Shanxi province. The average age of the subjects is about 17 years old.

There are 53 subjects from High School Affiliated to Southwest University and they are from class 8, the best arts class. As for the 65 subjects from class 6 of Jianshan Middle School and 55 subjects from class 1 of Datong Locomotive Middle School, they are from science classes. Both of the classes are the key classes of the school.

\subsection{Instruments}

\subsubsection{Translation Test}

This test aims to investigate the students' learning of transferred negation in TEFL, so doing translation in Appendix A is a direct way to know about whether students understand the meaning of the sentences. The test is researcher-made and checked for the validity and reliability in pilot tests. There are two parts in the English-Chinese translation test. Demographic information is collected in the first part, including grade, class number, gender and student number. Knowing the number of class can help the researchers to know whether the subjects are from a science class or an arts class, from the same area or not. Getting information about gender is to get more information about the participants and compare subjects of different gender. As for the student number, it is for the matching of the translation test and the questionnaire investigation.

The 20 sentences can be divided into two types: complex sentences and simple sentences. Sentence 1, 2, 3, 7, 9 , 18 and 20 are of the first type. Sentences 1,2 and 20 are of the most typical type of transferred negation, that is, the structure of "I don't think/ believe / suppose...". This kind of sentences can show whether students mastered the most basic type of sentence structure. Although it seems that the structure of sentence 9 is different from the previous sentences, its translation is of the typical type for the sentence still express one's opinion. Sentence 3 is a because-clause which is usually misinterpreted, which is used to show whether students understand the special meaning of the sentence. Sentence 7 and 18 are of another structure, that is, “...don't seem (look, sound, feel) + that..." The negation is in the main cause in form but in the subordinate clause in meaning. When translating these sentences, one should pay attention that the negation should be transferred from the main clauses.

The other sentences are the simple sentences. When words like all, both, every are used with the negative word "no", language learners are liable to make mistakes here because it might make the meaning partially affirmative or partially negative. Sentences 4, 5 and 6 are of this kind of transferred negation. Sentence 8 is of a type of transferred negation that is caused by the copula verb. The transferred negations of sentences $10,11,16,17$ are caused by the use of words like pretend, happen, remember and consider. Sentence 12 is a little difficult for it implies double negation which may confuse the learners. The negation of sentences 13,14 and 19 is on the adverbial part instead of the part that is next to the negative word. As for the sentence 15, there is a word implying negation without negative operator.

\subsubsection{Questionnaire}

The questionnaire investigation in Appendix B aims to get information about the students' thoughts about the translation. It would provide some background information for the analysis of the reasons. This questionnaire is designed by the researchers and ensured with the validity and reliability in pilot tests. Like the translation test, questionnaire is also composed of two parts but the whole questionnaire is in Chinese for students can understand it better. Demographic information is collected in the first part and there are 10 multiple choices in the second part. The demographic information collected in the first part keeps the same as that in translation test.

\subsection{Research Procedure}

All the subjects in the study were given the translation test paper and questionnaire at the same time. And then they were required to finish the translation test first and then the questionnaire. The translation of the sentences was the result of their first thought. The whole study was under the guidance of the researchers or the English teacher of the class.

The study on subjects from High School Affiliated to Southwest University was carried out on Dec. 12th, 2013. On Dec. 20th, the study on subjects from Jianshan Middle School was made. And students from Datong Locomotive Middle School received the survey on Dec. 30th.

The data of the translation test and questionnaire investigation were analyzed separately. For the translation part, all the translation was classified as four groups and marked with letters A, B, C or D according to their 
classifications. For example, for the first sentence "I don't think that he is honest", if the translation is like Wo bu renwei... (我不认为....... I don't think...), it would be marked as A. If the participant translated the sentence into Wo renwei...bu... (我认为..... 不...... I think...not...), it will be marked as B which means less acceptable. If the participant did not understand the meaning very clearly and made an obvious mistake, it would be divided into C. At last, if the student did not translate the sentence at all, it would be D. Then the data were analyzed and the results of the analysis are discussed in the following part.

\section{Data Analyses}

\subsection{Data Analyses of the Translation Test}

\subsubsection{Data Analyses of the Translation Test in the Complex Sentences}

The sentences have been divided into different types and groups, and the result of the study will be shown according to this classification. In most conditions, very few translations are marked into level C and level D and this study focuses on the level A and level B, so the data of C and D would not be shown on the following tables.

The first group of sentences is sentences 1, 2 and 20, the most typical type of transferred negation. Junior school students have been taught about the sentence structure like "I don't think...", so this group is of the most basic type. The frequencies of the first group in the translation test are shown in Table 1.

Table 1. Frequencies of different interpretations for sentences 1, 2, and 20

\begin{tabular}{|c|c|c|c|c|c|c|c|c|c|c|c|c|}
\hline \multirow{2}{*}{$\begin{array}{l}\text { Number of } \\
\text { Sentences }\end{array}$} & \multicolumn{4}{|c|}{ Class 1} & \multicolumn{4}{|c|}{ Class 6} & \multicolumn{4}{|c|}{ Class 8} \\
\hline & $\mathrm{A}$ & & B & & $\mathrm{A}$ & & $\mathrm{B}$ & & A & & B & \\
\hline 1 & 11 & $20 \%$ & 44 & $80 \%$ & 42 & $65 \%$ & 23 & $35 \%$ & 15 & $28 \%$ & 38 & $72 \%$ \\
\hline 2 & 30 & $55 \%$ & 25 & $45 \%$ & 52 & $80 \%$ & 13 & $20 \%$ & 35 & $66 \%$ & 18 & $34 \%$ \\
\hline 20 & 33 & $60 \%$ & 17 & $31 \%$ & 46 & $71 \%$ & 13 & $20 \%$ & 23 & $43 \%$ & 29 & $55 \%$ \\
\hline
\end{tabular}

However, the result is out of expectation of the researchers. As is shown in Table 1, most students did not translate the sentence correctly. The worst is class 6 , more than half the students made mistakes in translating this type of the sentence. For sentence 1, students of class 1 did well but they did not use the right structure to translate sentence 2 and sentence 20 . As for class 8 , most of the students understand the type of sentence.

In order to make a clearer comparison between these three sentences, the general result is counted. $61 \%$ students $(44+23+38 / 173)$ tended to write the preferred translation of sentence 1 while $39 \%$ students $(11+42+15 / 173)$ did not translate in the preferred way. As for sentence 2 and sentence 20, the ratios of subjects who did the right translation items are $32 \%(25+13+18 / 173)$ and $34 \%(17+13+29 / 173)$. We can see that except for the first sentence, most of the subjects made mistakes in translating the basic type of sentence. When the sentence becomes more complicated and the verb changes from think, the most typical verb, into believe and suppose, students may fail to pay attention to the transferred negation structure.

The next kind of sentence is sentence 9, in which transferred negation is caused by the predicative in the matrix clause as such nouns like wish, opinion and so on. This kind of sentence expresses opinion or belief. The translation condition is shown in Table 2.

Table 2. Frequencies of different interpretations for sentences 9

\begin{tabular}{|c|c|c|c|c|c|c|c|c|c|c|c|c|}
\hline \multirow{2}{*}{$\begin{array}{l}\text { Number of } \\
\text { Sentence }\end{array}$} & \multicolumn{4}{|c|}{ Class 1} & \multicolumn{4}{|c|}{ Class 6} & \multicolumn{4}{|c|}{ Class 8} \\
\hline & A & & B & & $\mathrm{A}$ & & B & & A & & B & \\
\hline 9 & 51 & $93 \%$ & 3 & $5 \%$ & 47 & $72 \%$ & 16 & $25 \%$ & 49 & $92 \%$ & 2 & $4 \%$ \\
\hline
\end{tabular}

It is quite clear that most students did not refer to the transferred negation when translating the sentence. The preferred translation of the sentence is like Wo xiwang/Wo de xiwang shi...bu... (我希望/我的希望是......不......, I wish/My wish is...not...). However, most students translated the sentence into Wo bu xiwang... (我不希望......., I don't wish...). The reason may be that students are more familiar with the Chinese expression like Wo bu... (我 不....., I don't...) rather than Wo...bu... (我.....不....., I...don't...). 
When because-clause is to be negated, the negative operator "not" is generally transferred to the matrix clause. Sentence 3 is of this kind of transferred negation. The translation should be like ...bushi yinwei... (......不是因 为 ...........not because...) instead of ...bu ...shi yinwei... (..... 不......是因为..........not...because...). This can be observed from the following Table 3 .

Table 3. Frequencies of different interpretations for sentences 3

\begin{tabular}{|c|c|c|c|c|c|c|c|c|c|c|c|c|}
\hline \multirow{2}{*}{$\begin{array}{l}\text { Number of } \\
\text { Sentence }\end{array}$} & \multicolumn{4}{|c|}{ Class 1} & \multicolumn{4}{|c|}{ Class 6} & \multicolumn{4}{|c|}{ Class 8} \\
\hline & A & & B & & A & & B & & A & & B & \\
\hline 3 & 53 & $96 \%$ & 1 & 1 & 60 & $92 \%$ & 2 & $3 \%$ & 51 & $96 \%$ & 1 & $2 \%$ \\
\hline
\end{tabular}

In general, $85 \%(51+47+49 / 173)$ subjects failed to give the preferred translation for sentence 9 and only $2 \%$ students wrote the preferred translation for sentence 3 . The results of data analysis for sentence 3 and sentence 9 show that without an awareness of the structure, students tend to make mistakes in understanding and translating the sentence.

The last group of sentences in this part is sentence 7 and sentence18. For these two sentences, the main verb in the matrix clause is a median-value verb. The translation for sentence 7 should be like Kan qilai/Sihu...bu... (看 起来/似乎......不......, It seems... not...). As for sentence 18, the Chinese translation is Keneng...bu... (可能...... 不....., may...not...). As seen in the following Table 4.

Table 4. Frequencies of different interpretations for sentences 7 and 18

\begin{tabular}{|c|c|c|c|c|c|c|c|c|c|c|c|c|}
\hline \multirow{2}{*}{$\begin{array}{l}\text { Number of } \\
\text { Sentence }\end{array}$} & \multicolumn{4}{|c|}{ Class 1} & \multicolumn{4}{|c|}{ Class 6} & \multicolumn{4}{|c|}{ Class 8} \\
\hline & $\mathrm{A}$ & & B & & $\mathrm{A}$ & & B & & $\mathrm{A}$ & & B & \\
\hline 7 & 2 & $4 \%$ & 51 & $93 \%$ & 7 & $11 \%$ & 55 & $85 \%$ & 3 & $6 \%$ & 47 & $87 \%$ \\
\hline 18 & 33 & $60 \%$ & 15 & $27 \%$ & 8 & $12 \%$ & 40 & $62 \%$ & 3 & $6 \%$ & 50 & $94 \%$ \\
\hline
\end{tabular}

We can see that most of the students translate the sentence 7 well and students in class 6 and 8 also understand the sentence 18 well, better than students from class 1 . The general result shows that most students understand this kind of transferred negation sentences well. The ratios of students who wrote the right translation of the two sentences are $88 \%(51+55+47 / 173)$ and $61 \%(15+40+50 / 173)$.

\subsubsection{Data Analyses of the Translation Test in the Simple Sentences}

Transferred negation in the simple sentence refers to the occurrence of negation transfer in the simple sentence or just in the subordinate clause and do not cross the matrix clause and the subordinate clause. Sentences 4, 5, and 6 consist of the first group, and the frequencies of different interpretations are show in Table 5.

Table 5. Frequencies of Different Interpretations for Sentences 4, 5 and 6

\begin{tabular}{|c|c|c|c|c|c|c|c|c|c|c|c|c|}
\hline \multirow{2}{*}{$\begin{array}{l}\text { Number of } \\
\text { Sentence }\end{array}$} & \multicolumn{4}{|c|}{ Class 1} & \multicolumn{4}{|c|}{ Class 6} & \multicolumn{4}{|c|}{ Class 8} \\
\hline & A & & B & & A & & B & & A & & B & \\
\hline 4 & 55 & $100 \%$ & 1 & 1 & 46 & $71 \%$ & 15 & $23 \%$ & 31 & $58 \%$ & 20 & $38 \%$ \\
\hline 5 & 55 & $100 \%$ & I & 1 & 61 & $94 \%$ & 4 & $6 \%$ & 46 & $87 \%$ & 7 & $13 \%$ \\
\hline 6 & 37 & $67 \%$ & 17 & $31 \%$ & 12 & $18 \%$ & 50 & $77 \%$ & 21 & $40 \%$ & 31 & $58 \%$ \\
\hline
\end{tabular}

The above Table 5 shows that all the students in class 1 thought that the negative word "not" was used to negate the following verb. While $71 \%$ of students in class 6 and $58 \%$ of students from class 8 also held the same opinion. The situation of sentence 5 is like sentence 4 . But for sentence 6 , more students from class 6 and 8 produced the translation that "not" negates "everybody" but more students from class 1 tended to think that "not" negates the verb. And from the general result, we can conclude that this kind of sentence is a difficulty for students. $20 \%(15+20 / 173)$ students translated well for sentence 4 and only $6 \%(4+7 / 173)$ students translated 
correctly for sentence 5 . For sentence 6 , the ratio is $57 \%(17+50+31 / 173)$.

The transferred negation of sentence 8 is caused by the copula verb "taste". The translation is ...chang qilai bu... (......尝起来不..........taste not...).

Table 6. Frequencies of different interpretations for sentences 8

\begin{tabular}{|c|c|c|c|c|c|c|c|c|}
\hline \multirow{2}{*}{$\begin{array}{l}\text { Number of } \\
\text { Sentence }\end{array}$} & \multicolumn{3}{|l|}{ Class 1} & \multicolumn{3}{|c|}{ Class 6} & \multicolumn{2}{|l|}{ Class 8} \\
\hline & $\mathrm{A}$ & B & & A & B & & A & B \\
\hline 8 & 1 & 55 & $100 \%$ & 1 & 62 & $95 \%$ & 1 & $52 \quad 98 \%$ \\
\hline
\end{tabular}

It is obvious from Table 6 that students almost have no difficulty in understanding the sentence.

Sentence 12 is a little difficult when trying to understand the sentence. The structure is not complicated but it has double negation in the sentence. The preferred negation is like Dale zhaohu wo.../Wo buhui bu da zhaohu jiu... (打了招呼，我......我不会不打招呼就......, After the greeting, I.../I would not...without greeting).

Table 7. Frequencies of different interpretations for sentences 12

\begin{tabular}{|c|c|c|c|c|c|c|c|c|c|c|}
\hline \multirow{2}{*}{$\begin{array}{l}\text { Number of } \\
\text { Sentence }\end{array}$} & \multicolumn{3}{|l|}{ Class 1} & \multicolumn{3}{|l|}{ Class 6} & \multicolumn{4}{|c|}{ Class 8} \\
\hline & $\mathrm{A}$ & B & & $\mathrm{A}$ & B & & A & & B & \\
\hline 12 & $18 \quad 33 \%$ & 21 & $38 \%$ & $13 \quad 20 \%$ & 20 & $31 \%$ & 7 & $13 \%$ & 33 & $62 \%$ \\
\hline
\end{tabular}

From Table 7, 62\% of students of class 8 translated the sentence in the preferred way but for class 1 and class 6 , the percentages are $38 \%$ and $31 \%$.

For sentence 15, it has no negative operator but it expresses negative meaning. And the Table 8 shows clearly that students understand the meaning of the sentence well.

Table 8. Frequencies of different interpretations for sentences 15

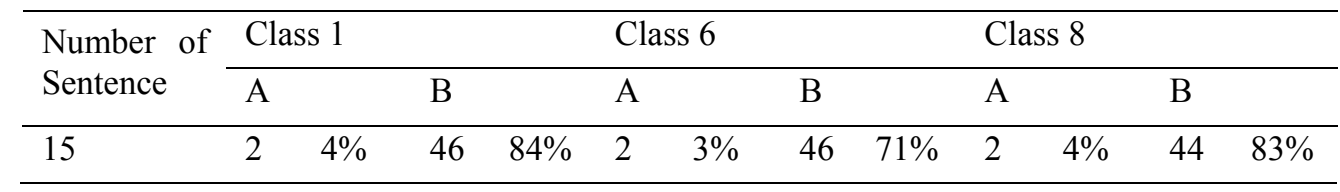

After count the general result, we can see student master these three kinds of transferred negation well. The ratios of students who translated the sentences correctly are $98 \%(55+62+52 / 173), 43 \%(21+20+33 / 173)$ and $79 \%(46+46+44 / 173)$.

For some sentences, negative objects are actually the infinitive structure or the objective complements. The negation of sentences 10,11 16 and 17 is of this situation.

Table 9. Frequencies of different interpretations for sentences 10, 11, 16 and 17

\begin{tabular}{lllllllllllll}
\hline \multirow{2}{*}{$\begin{array}{l}\text { Number of } \\
\text { Sentence }\end{array}$} & \multicolumn{1}{l}{ Class 1 } & \multicolumn{4}{c}{ Class 6 } & \multicolumn{5}{c}{ Class 8 } \\
\cline { 2 - 13 } & A & & B & & A & & B & & A & & B \\
\hline 10 & 17 & $31 \%$ & 35 & $64 \%$ & 44 & $68 \%$ & 13 & $20 \%$ & 37 & $70 \%$ & 14 & $26 \%$ \\
11 & 15 & $27 \%$ & 33 & $60 \%$ & 30 & $46 \%$ & 10 & $15 \%$ & 18 & $34 \%$ & 14 & $26 \%$ \\
16 & 43 & $78 \%$ & 8 & $15 \%$ & 60 & $95 \%$ & 1 & $2 \%$ & 47 & $89 \%$ & 7 & $13 \%$ \\
17 & 20 & $36 \%$ & 32 & $58 \%$ & 50 & $77 \%$ & 9 & $14 \%$ & 28 & $53 \%$ & 24 & $45 \%$ \\
\hline
\end{tabular}


The preferred translation of sentence 10 is Jiazhuang bu... (假装不......, pretend not...). 64\% students from class 1 gave this translation. But only $20 \%$ students from class 6 and $26 \%$ students from class 8 translated so. The situation of sentence 11 is like sentence 10. Most students from class 1 translated the sentence like Qiaqiao/Pengqiao bu... (恰巧/碰巧不......, happen not...). But 46\% students from class 6 and 34\% students from class 8 did not translate like this. For sentence 16, the translation is Jide bu/mei... (记得不/没......, remember...not...) instead of Bu jide...(不记得......, don't remember...). The suitable translation of sentence 17 is ...renwei...bu... (..... 认为...... 不..........think...not...) rather than ...bu renwei... (..... 不认为......, ...don't think...). In class 1, 78\% students gave the latter translation and 15\% students gave the former. In class $6,95 \%$ students gave the latter while only $2 \%$ gave the former. For class $8,89 \%$ students wrote the latter and $13 \%$ students wrote the former. For sentence $17,58 \%$ students translated correctly and $36 \%$ students produced the unpreferred structure. In class 6 , only $14 \%$ students translated correctly and $77 \%$ students produced the latter translation. In class $8,53 \%$ students gave the latter translation while $45 \%$ gave the former. The general result shows that students did not translate this group that well. $36 \%(35+13+14 / 173)$ students produced preferred translation for sentence 10 and $33 \%(33+10+14 / 173)$ for sentence 11 . As for sentences 16 and 17 , the ratios are $9 \%(8+1+7 / 173)$ and $38 \%(32+9+24 / 173)$.

The last group of sentences is composed of sentences 13,14 and 19. The real negative objects for these sentences are the adverbial phrases.

Table 10. Frequencies of different interpretations for sentences 13, 14 and 19

\begin{tabular}{|c|c|c|c|c|c|c|c|c|c|c|c|c|}
\hline \multirow{2}{*}{$\begin{array}{l}\text { Number of } \\
\text { Sentence }\end{array}$} & \multicolumn{4}{|c|}{ Class 1} & \multicolumn{4}{|c|}{ Class 6} & \multicolumn{4}{|c|}{ Class 8} \\
\hline & A & & B & & A & & B & & A & & B & \\
\hline 13 & I & 1 & 51 & $93 \%$ & 1 & $2 \%$ & 25 & $38 \%$ & 1 & $2 \%$ & 47 & $87 \%$ \\
\hline 14 & I & I & 48 & $87 \%$ & 3 & $5 \%$ & 59 & $91 \%$ & 1 & $2 \%$ & 52 & $98 \%$ \\
\hline 19 & 3 & $5 \%$ & 47 & $85 \%$ & 6 & $9 \%$ & 48 & $74 \%$ & 3 & $6 \%$ & 44 & $83 \%$ \\
\hline
\end{tabular}

The students from class 6 did not translate sentence 13 well but for the rest subjects, they translated the sentences as the preferred structure. In general, most students understand the meaning of these sentences. The ratios of students who translated correctly are $71 \%(51+25+47 / 173), 92 \%(48+59+52 / 173)$ and $80 \%(47+48+44 / 173)$.

\subsection{Data Analyses of the Questionnaire Investigation}

The questionnaire is composed of 10 questions and the analysis of the answers would provide some background information for the reason analysis. The data of each class would be analyzed and then the general result of subjects would also be shown in the following tables.

The first question is "Do you often see such sentences in your English study?" It talks about whether it is a common grammar phenomenon for these students. The result is shown in the following Table 11.

Table 11. Frequencies of question 1 for students from each class

\begin{tabular}{llllll}
\hline & A. always & B. sometimes & C. unclear & D. seldom & E. never \\
\hline Class 1 & $33 \%$ & $40 \%$ & $7 \%$ & $15 \%$ & $5 \%$ \\
Class 6 & $21 \%$ & $54 \%$ & $11 \%$ & $9 \%$ & $5 \%$ \\
Class 8 & $2 \%$ & $44 \%$ & $7 \%$ & $40 \%$ & $7 \%$ \\
\hline
\end{tabular}

For the first question, A stands for that they always see the sentences of transferred negation while B stands for that they sometimes see this kind of sentences. In class $1,33 \%$ students chose A and $40 \%$ students chose B. In class $6,21 \%$ students chose A and 54\% students chose B. For the two science classes, most students often meet transferred negation sentences. But the situation is different for the arts class. Only $2 \%$ students chose A and $44 \%$ students chose B. $40 \%$ of students chose that they seldom see the grammar phenomenon. Like the analysis of the translation test, the general result of the questionnaire investigation is also counted to have a more comprehensive analysis of the data. In general, $18 \%(18+1+12 / 173)$ of them always see transferred negation sentences and $44 \%(22+24+30 / 173)$ of them sometimes see them. So the phenomenon is common for these 
students in general.

The third question is about the current teaching situation of the grammar. From the answer, we can see whether the teachers focus on the grammar concept.

Table 12. Frequencies of question 3 for students from each class

\begin{tabular}{llllll}
\hline & A. very much & B. comparatively & C. sometimes & D. average & E. never \\
\hline Class 1 & $43 \%$ & $45 \%$ & $5 \%$ & $5 \%$ & $2 \%$ \\
Class 6 & $17 \%$ & $47 \%$ & $11 \%$ & $21 \%$ & $4 \%$ \\
Class 8 & $4 \%$ & $51 \%$ & $0 \%$ & $36 \%$ & $9 \%$ \\
\hline
\end{tabular}

The letter A stands for that the teacher pays highly attention to the grammar while B stands for that the teacher pays attention to it. $88 \%(43 \%+45 \%)$ students from class 1 chose A and B while $64 \%(17 \%+47 \%)$ students from class 6 chose them. In class $8,55 \%(4 \%+51 \%)$ chose them. So we can reach a conclusion that although transferred negation is not a key grammar concept for senior high school students, teachers still focus on it. From the general result, $70 \%(11+31+2+28+24+25 / 173)$ students chose A and B.

Question 8 is about students' ability of using transferred negation. The question is whether students would use transferred negation structure when writing a composition.

Table 13. Frequencies of question 8 for students from each class

\begin{tabular}{llllll}
\hline & A. always & B. sometimes & C. unclear & D. seldom & E. never \\
\hline Class 1 & $7 \%$ & $29 \%$ & $7 \%$ & $56 \%$ & $0 \%$ \\
Class 6 & $8 \%$ & $37 \%$ & $14 \%$ & $39 \%$ & $2 \%$ \\
Class 8 & $11 \%$ & $36 \%$ & $9 \%$ & $44 \%$ & $0 \%$ \\
\hline
\end{tabular}

Letter B means that students sometimes use the structure and letter D means that they seldom use it. $29 \%$ students from class 1 chose B while $56 \%$ students chose D. $37 \%$ students from class 6 chose B and $39 \%$ chose D. As for class $8,36 \%$ students chose B and $44 \%$ chose D.

According to the general result, we can conclude that many students are not familiar with transferred negation structure and they do not have the awareness of using it. Only $9 \%(6+6+4 / 173)$ students often use the structure while $84 \%(26+28+20+24+16+31 / 173)$ students chose B or D.

The rest questions aim to collect some information about students' thoughts when they were doing the translation test. Question 2 focuses on the general impression of the translation test. The question is "Do you feel it difficult to translate these sentences?" The results are shown in the following Table 14.

Table 14. Frequencies of question 2 for students from each class

\begin{tabular}{llllll}
\hline & A. very much & B. a little & C. so-so & D. easy & E. very easy \\
\hline Class 1 & $11 \%$ & $36 \%$ & $35 \%$ & $15 \%$ & $3 \%$ \\
Class 6 & $2 \%$ & $42 \%$ & $44 \%$ & $9 \%$ & $3 \%$ \\
Class 8 & $2 \%$ & $11 \%$ & $62 \%$ & $25 \%$ & $0 \%$ \\
\hline
\end{tabular}

Students hold different opinions towards the test. In class $1,11 \%$ students thought that the test is very difficult. $36 \%$ students thought it a little difficult while $35 \%$ students not so difficult. In class 6 , only $2 \%$ students thought it very difficult. $42 \%$ thought it a little difficult and $44 \%$ not so difficult. For class 8 , the percentages of the three situations are $2 \%, 11 \%$ and $62 \%$. Students in Chongqing regarded the test as not so difficult in general. On the whole, $47 \%(29+34+19 / 173)$ students thought that the test is not so difficult and $16 \%(6+14+8 / 173)$ thought that the test is easy. The test is not so difficult for them and the test is valid. 
Question 4 and question 5 are about the negative part of the sentences. Question 4 is "Are you sure of the objects of negation in the sentences?" and question 5 is "Will you think about the objects of negation before you translate such sentences?"

Table 15. Frequencies of question 4 for students from each class

\begin{tabular}{llllll}
\hline & A. completely & B. comparatively & C. not completely & D.unsure & E. very unsure \\
\hline Class 1 & $18 \%$ & $67 \%$ & $11 \%$ & $4 \%$ & $0 \%$ \\
Class 6 & $3 \%$ & $73 \%$ & $15 \%$ & $9 \%$ & $0 \%$ \\
Class 8 & $7 \%$ & $85 \%$ & $2 \%$ & $5 \%$ & $0 \%$ \\
\hline
\end{tabular}

Table 16. Frequencies of question 5 for students from each class

\begin{tabular}{llllll}
\hline & A. always & B. sometimes & C. unclear & D. seldom & E. never \\
\hline Class 1 & $33 \%$ & $31 \%$ & $24 \%$ & $7 \%$ & $5 \%$ \\
Class 6 & $21 \%$ & $41 \%$ & $15 \%$ & $18 \%$ & $5 \%$ \\
Class 8 & $16 \%$ & $60 \%$ & $11 \%$ & $9 \%$ & $4 \%$ \\
\hline
\end{tabular}

Most students are sure about the objects of negation in the sentences and would think about the objects of negation before translating. $84 \%(18 \%+67 \%)$ students are completely or comparatively sure of the objects of negation in the sentences and $64 \%(33 \%+31 \%)$ students often think about the objects of negation before they translate such sentences.

Questions 6 and question 7 compare transferred negation in English with Chinese. The questions are "Do you think the expressing way of the negation in these sentences is the same as that of Chinese?" and "Will you be influenced by the habit of Chinese expression when interpreting the sentences?"

Table 17. Frequencies of question 6 for students from each class

\begin{tabular}{llllll}
\hline & A. none & B. 1-5 & C. 6-10 & D. 11-15 & E. over 15 \\
\hline Class 1 & $7 \%$ & $47 \%$ & $38 \%$ & $5 \%$ & $3 \%$ \\
Class 6 & $21 \%$ & $41 \%$ & $15 \%$ & $18 \%$ & $5 \%$ \\
Class 8 & $2 \%$ & $34 \%$ & $4 \%$ & $13 \%$ & $2 \%$ \\
\hline
\end{tabular}

Table 18. Frequencies of question 7 for students from each class

\begin{tabular}{llllll}
\hline & A. very much & B. to some degree & C. unclear & D. seldom & E. never \\
\hline Class 1 & $20 \%$ & $62 \%$ & $12 \%$ & $5 \%$ & $1 \%$ \\
Class 6 & $17 \%$ & $65 \%$ & $8 \%$ & $9 \%$ & $1 \%$ \\
Class 8 & $11 \%$ & $71 \%$ & $4 \%$ & $14 \%$ & $0 \%$ \\
\hline
\end{tabular}

For students from class $1,47 \%$ thought that the negation of 1 to 5 sentences is the same as that of Chinese while $38 \%$ thought that the negation of 6 to 10 sentences is the same as that of Chinese. For class 6 , the percentages are $41 \%$ and $15 \%$. In addition, $21 \%$ students thought that none of the negation of these sentences are the same to that of Chinese. In class 8 , the percentages are $34 \%$ and $4 \%$.

As for the influence on the habit of Chinese expression, $20 \%$ students from class 1 chose $\mathrm{A}$, meaning that Chinese has great effect on their interpretation. $62 \%$ chose $\mathrm{B}$, which refers to that Chinese has effect on their translation. 17\% students from class 6 chose A while $65 \%$ chose B. In class $8,11 \%$ chose A and $71 \%$ chose B.

$85 \%(4+16+31+1+18+26+4+26+21 / 173)$ students thought that the negation of several sentences in the translation test is the same as that of Chinese. And $86 \%(11+43+6+40+12+37 / 173)$ of students thought that the 
habit of Chinese expression did have influence on them.

Next is question 9 and question 10. The last two questions focus on the difficulties and key points of translation.

Table 19. Frequencies of question 9 for students from each class

\begin{tabular}{llll}
\hline & A. new/complicated words & B. unfamiliar/complicated sentence structure & C. negation \\
\hline Class 1 & $49 \%$ & $26 \%$ & $25 \%$ \\
Class 6 & $40 \%$ & $41 \%$ & $19 \%$ \\
Class 8 & $25 \%$ & $24 \%$ & $51 \%$ \\
\hline
\end{tabular}

Table 20. Frequencies of question 10 for students from each class

\begin{tabular}{llll}
\hline & A. new words & B. sentence structure & C. negation \\
\hline Class 1 & $24 \%$ & $26 \%$ & $50 \%$ \\
Class 6 & $25 \%$ & $45 \%$ & $30 \%$ \\
Class 8 & $11 \%$ & $30 \%$ & $59 \%$ \\
\hline
\end{tabular}

For question 9, A refers that the difficulty of translation lies to the new words and complicated words. B means that they found that the unfamiliar sentence structure or the complicated structure made it difficult for them to translate the sentences. $\mathrm{C}$ stands for that the negation in the sentences is the difficulty. $49 \%$ students from class 1 chose A and $26 \%$ chose B. For class $6,40 \%$ chose A and $41 \%$ chose B. In class $8,51 \%$ chose $C$ and $25 \%$ chose A. So it seems that for the science classes, the major obstacle was not the negation but students from the arts class regarded negation as the major difficulty.

For question 10, A means that the key point of interpretation is new words. B stands for sentence structure and C the negation of sentences. $50 \%$ subjects from class 1 chose C. $24 \%$ chose A and $26 \%$ chose B. $45 \%$ students from class 6 chose C. $25 \%$ chose A and $30 \%$ chose B. For class 8 , the percentages are $59 \%, 11 \%$ and $30 \%$. In general, $63 \%(29+13+13+25+15+14 / 173)$ students thought that the sentence structure and the negation in the sentences caused difficulties for their understanding and $80 \%(14+27+17+33+29+19 / 173)$ chose that the key points of interpretation were these two factors. Students' translation depended a lot on the negation and the sentence structure.

\subsection{Summary}

\subsubsection{Summary of the Translation Test}

Firstly, about the transferred negation in the complex sentences.

There are three groups of sentences in this part. For the first group, $80 \%$ and $45 \%$ students from class 1 presented the preferred translation for sentences 1 and $31 \%$ students translated sentence 20 correctly. The percentages for class 6 are $35 \%, 20 \%$ and $20 \%$. For class 8 , they are $72 \%, 34 \%$ and $55 \%$.

In the translation of sentence $9,5 \%$ subjects in class $1,25 \%$ in class 6 and $4 \%$ in class 8 presented the preferred translation. No students from class 1 produced the right structure for sentence 3 . As for class 6 and class 8 , the percentages are $3 \%$ and $2 \%$.

For the last group, $93 \%$ subjects in class $1,85 \%$ in class 6 and $87 \%$ in class 8 produced the right structure for sentence 7 . As for sentence 18 , the percentages are $27 \%, 62 \%$ and $94 \%$.

Secondly, about the transferred negation in the simple sentences.

Sentences 4, 5, and 6 are of the first group. In class 1, no one produced the right structure for sentences 4 and 5 . $31 \%$ of them translated in the right structure for sentence 6 . For subjects from class 6 , the percentages are $23 \%$, $6 \%$ and $77 \%$. For class 8 , they are $38 \%, 13 \%$ and $58 \%$.

For sentence $8,100 \%$ subjects in class $1,95 \%$ in class 6 and $98 \%$ in class 8 gave the right translation. For sentence $12,38 \%$ subjects in class $1,31 \%$ in class 6 and $62 \%$ in Class 8 gave the preferred translation. As for sentence $15,84 \%$ subjects in Class $1,71 \%$ in class 6 and $83 \%$ in class 8 translated the sentence correctly.

In the next group of transferred negation in the simple sentences, $64 \%$ students in class 1 produced the preferred 
translation. But only $20 \%$ students from class 6 and $26 \%$ students from class 8 translated well. $60 \%$ in class 1 , $15 \%$ in class 6 and $26 \%$ in class 8 wrote the preferred translation of sentence 11 . For sentence 16, the ratios are $15 \%, 2 \%$ and $13 \%$. For sentence 17 , they are $58 \%, 14 \%$ and $45 \%$.

For the last group of sentences, the ratios for sentence 13 are $93 \%, 38 \%$ and $87 \%$. For sentence 14 , they are $87 \%$, $91 \%$ and $98 \% .85 \%, 74 \%$ and $83 \%$ are the results for sentence 19 .

\subsubsection{Summary of Questionnaire Investigation}

For most of subjects from class 1 and 6 , transferred negation was a common language phenomenon but for students from class $8,40 \%$ of them thought it was an uncommon language phenomenon. But in general, this grammar concept was common in their study. Teachers paid attention to the teaching of transferred negation sentences but students were still unfamiliar with the structure. Students had the awareness to make sure of the negative part of the sentence. However, the difference between Chinese and English led to some difficulties for them. Besides, other factors like new words and complicated sentence structure also caused difficulties for them.

\section{Discussion of the Data Analyses}

\subsection{Major Findings of the Research Result}

Firstly, students treated different kinds of transferred negation sentences differently.

1) For the typical kind of transferred negation sentences, when the verb was not think, students would not have the awareness that "not" with the main verb in the matrix clause actually negated the verb in the subordinate clause. For sentence 2, 32\% subjects produced the preferred translation. As for sentence 20, the ratio was lower. Only $17 \%$ students translated correctly.

2) For the transferred negation sentences that were caused by the predicative in the matrix clause, students preferred not to transfer "not" to that-clause in interpretation. In the translation test, $88 \%$ students failed to translate the sentence correctly.

3) When because-clause was to be negated, the negative operator "not" was generally transferred to the matrix clause. But it was difficult for students to realize it. Only 2 subjects from class 6 and 1 subject from class 8 translated in the preferred way.

4) For the structure like full affirmative + not + full affirmative made the meaning partially affirmative or partially negative, students tended to think that "not" negates the following verb. For sentence $4,20 \%$ subjects translated well while only $6 \%$ students produced the preferred translation for sentence 5 .

5) For the transferred negation structure like that negative objects were actually the infinitive structure, more students did not realize that "not" was used to negate the infinite structure. For sentences 10 and 11, the ratios of students who produced the right translation are $36 \%$ and $33 \%$.

6) When the negative parts were the objective complements, students tended to think that "not" was used to negate the predicate verb. For sentence 16, only $9 \%$ subjects gave the right translation and $36 \%$ translated well for sentence 17.

Secondly, the foundation of English had no direct relation to whether students were familiar with transferred negation structure. Students from class 8 score higher than other students, and they used the least time to finish the translation test. Therefore, it is natural to think that they would do a better job. However, the result is out of expectation. For sentences 1, 2, 10,11,13,16 and 17, students from class 1 translated best. For sentences 3, 6, 7, $8,9,14$ and 19, more subjects from class 6 produced the preferred translation. For sentence 15, both students from class 1 and class 6 translated well. For students from class 8 , they translated best for sentences $4,5,12,18$ and 20. In other words, students from class 1 or class 6 translated 8 sentences better while subjects from class 8 translated 5 sentences better. That is to say, students from class 1 and 6 did a better job than students from class 8 in the translation test. So getting higher sores does not mean mastering transferred negation structure better.

Thirdly, the difference between students from different schools was not so obvious but there existed very clear difference for some sentences and students from the same class tended to make mistakes in the same kind of transferred negation sentences. From the test of homogeneity (Sig. $=0.627$ ), we can find that it is safe to make a comparison between students from different schools but from the anova test $($ Sig. $=0.931)$, the difference was not very obvious in general. Sentence 4 and sentence 6 are of the type of sentence where the sentence structure is like full affirmative + not + full affirmative. None of the students from class 1 translated sentence 4 correctly but students from the other two classes translated much better. $9 \%$ students from class 6 and $12 \%$ students from class 8 produced the preferred translation. For sentence 6 , students from class 6 and class 8 also did a better job. For sentences 16 and 17, the negation objects are the objective complements and more students from class 6 tended 
to make mistakes in this type of sentences.

Fourthly, female students have an obvious advantage over male students in the translation test. Except for 2 subjects who did not offer information about their gender, the data of 171 subjects are analyzed. The number of students who wrote the preferred translation of each sentence is counted, and from the statistical analysis $(t=0.000167857, p<0.05)$ it is quite clear that girls did a much better job than boys. Except for sentence 9, more girls produced the preferred translation than boys for every sentence.

\subsection{Analysis of the Research Result}

When we combine the data of the translation test and questionnaire investigation together, we can get some reasons behind the number.

Firstly, students are easily influenced by the habits of Chinese expression. Students have little problems when translating the sentences $7,18,8,12,15,13,14$ and 19. These sentences are of transferred negation structure in broad sense but these sentences can be translated directly without thinking too much about the negation structure. For example, sentence 8 is “The food doesn't taste good." The preferred translation is Shiwu chang qilai bu hao (食物尝起来不好, The food tastes not good) and Chinese people get used to saying so. But for other sentences like sentence 2, "We don't believe that the news is true." If we translate the sentence into Women bu xiangxin xiaoxi shi zhenshi de (我们不相信消息是真实的), it is an acceptable sentence in Chinese. Therefore, it is easy for students to ignore the grammar phenomenon.

Secondly, the study motivation has an impact on the effects of study. As teachers mentioned, they have taught the grammar but students may not get enough exercise about it. For most Chinese students, getting higher scores is their goal to study. Not being a key grammar concept equals to ignorance sometimes. So for students, without a clear goal to study the language may lead to a bad study result.

Thirdly, students do not have a systematic knowledge structure of the grammar concept. This test covers many different types of transferred negation sentences and students were confused. Although they had the awareness to make sure of the negative part of the sentence, they were lack of enough knowledge to help them understand sentences. Students from different schools, different classes or even different places would vary from each other. But it is no doubt that they all need a systematic knowledge structure to deepen their understanding and broaden their eyes.

Fourthly, vocabulary plays a great role in studying a foreign language. Without a large amount of vocabularies, language learners would lose their way. They will be at a loss facing the new language phenomena. For example, in the translation test, some students did not know the meaning of "cock" and "crow" and they translated the sentence into naozhong xiang (闹钟响, The bell is ringring.) or chushi zuofan (㕑师做饭, The cook is working.). The questionnaire investigation also shows that vocabulary is a key factor for students to understand these sentences. To be a successful learner means that one should be aware of the importance of studying new words.

\section{Conclusion}

It could be concluded that students mainly have problems with the typical kind of transferred negation sentences, the negation caused by the predicative in the matrix clause, the negation of because-clause, the negation of infinitive structure or the objective complements and so on. The language foundation of English has no direct relation to whether students are familiar with transferred negation structure. There exists a very clear difference between students from different schools for some sentences and students from the same class tend to make mistakes in the same kind of transferred negation sentences. Female students have an advantage over male students in the translation test. Some factors like the habits of Chinese expression have great effects on students' understanding of the structure.

For English language teaching in mainland China, there are three suggestions about the question of transferred negation. The first suggestion is that students and teachers build an idea that learning a foreign language is like building an organic system. A language learner should pay attention to every step of his or her construction. Although having a steady foundation is a great advantage, it does not mean that you can relax or even ignore the future study. From the data analyses we can find that the study foundation has no direct relation to whether students are familiar with transferred negation. Students who get higher scores did not behave better in the translation test. Every language has its own characteristics, which needs language learners to pay attention to. Secondly, teachers take the differences between students seriously and try to find effective teaching methods that are suitable for most students. According to the data analyses, female students had an overwhelming advantage over male students in the translation test. For the 20 sentences in the translation test, boys only translated one sentence better than girls. Students have different learning backgrounds, learning habits and so on. A teacher 
needs to observe his or her students and try to find the most effective teaching method. Thirdly, teachers pay attention to the influence of mother tongue. The translation items of different kinds of transferred negation sentences were pretty different. When the expressing approach is like Chinese, most students can translate well and vice versa. From the analysis of questionnaire investigation, $82 \%$ students thought that the habit of Chinese expression has effect on their understanding of the sentences.

The main limitation of this study is about the number of subjects. The initial design of this study was to compare students from different grades and analyze their difference. Then reasons of their difference would be analyzed from the angle of cognitive linguistics. However, for the students from grade 3 were busy with their study, the design of the research had to be revised. The final design is to compare students from the same grade and the total number of subjects is 173 , and a larger number of subjects would help to clarify the questions about the complexity of this language phenomenon in TEFL.

\section{References}

Brown, P., \& Levinson, S. C. (1987). Politeness: Some universals in language usage. Oxford: Cambridge University Press.

Bybee, J., Perkins, R., \& Pagliuca, W. (1994). The evolution of grammar: Tense, aspect, and modality in the languages of the world. Chicago: University of Chicago Press.

Cao, B. (2006). Investigation into ambiguity by scope of negation (Unpublished master's thesis). Dalian Maritime University, Dalian, Liaoning, China.

Chen, P. (2005). An adaptation-based pragmatics approach to transferred negation (Unpublished master's thesis). Hangzhou Normal University, Hangzhou, Jiangsu, China.

Chen, P. (2005). The grammaticalization of "transferred negation" in English. Journal of Zhejiang Education Institute, 4, 58-62.

Chen, X. (2002). Internal relations between transferred negation and linguistic politeness. Journal of Changde Teachers University (Social Science Edition), 27(4), 84-85.

Foley, M., \& Hall, D. (2005). Longman advanced learners' grammar. London: Longman.

Foley, W. A. (1997). Anthropological linguistics: An introduction. Oxford: Blackwell Publishing Ltd.

Horn, L. R. (1978). Remarks on neg-raising. In P. Cole (Ed.), Syntax and semantics 9: Pragmatics (pp. 129-220). New York: Academic Press.

Lian, S.-N. (2006). A coursebook on English-Chinese translation. Beijing: Higher Education Press.

Liu, X.-Y. (2011). An investigation on Chinese students'learning of English transferred negation at Zhumadian No.1 senior middle school (Unpublished master's thesis). Henan University, Kaifeng, Henan, China.

Morante, R., \& Sporleder, C. (2012). Modality and negation: An introduction to the special issue. Computational linguistics, 38(2), 223-260.

Quirk, R. et al. (1972). A grammar of contemporary English. London: Longman.

Quirk, R. et al. (1985). A comprehensive grammar of the English language. New York: Longman Group Limited.

Svartvik, J., \& Quirk, R. (1980). A corpus of English conversation. Lund, Sweden: Gleerup.

Xiang, Z.-Q. (1999). Transferred negation in English negative sentences. Journal of Hefei University of Technology (Social Science Edition), 1, 100-106.

Xiong, X.-L. (1988). A discussion of transferred negation in English. Modern Foreign Languages, 4, 54-61.

\section{Appendixes}

Appendix A. Translation Test

The following translation test paper is designed for the research on the way Chinese students interpret transferred negation sentences. Please do each item carefully. All the data collected will be highly confidential and will be used for the research only. Thanks for your cooperation.

Part A. Background Information

Grade:

Class: 
Gender:

Student ID:

Part B. Translation

There are some English sentences below. Please translate the following sentences into Chinese.

1) I don't think that he is honest.

2) We don't believe that the news is true.

3) I don't teach because teaching is easy for me.

4) All these nations are not neutral.

5) Both of the sisters are not here.

6) Everybody is not fit for art.

7) It doesn't seem that it will rain.

8) The food doesn't taste good.

9) It is not my wish that you should go to America.

10) I didn't pretend to understand what she said.

11) I didn't happen to understand what she said.

12) I didn't step into the well-known boat without a greeting.

13) The cock had a strange habit. It did not crow at dawn, but at midnight.

14) Rome was not built in a day.

15) You need to say nothing about the event.

16) I don't remember having ever seen such a man.

17) They don't consider him a good man.

18) It is not likely that he will come to the party.

19) I'm not speaking with hatred.

20) I don't suppose he will return to his hometown after a few years of study abroad.

\section{Appendix B. Questionnaire}

The questionnaire investigation aims to get some information about your understanding of transferred negation. The information collected is only for the research and all the data collected will be highly confidential. Please read each item carefully and finish the questionnaire honestly. Thanks for your cooperation.

Part 1. Background Information

Grade:

Class:

Gender:

Student ID:

Part 2. Questionnaire

There are 10 questions below. Please choose the most suitable answer for each question according to your situation.

( ) 1. Do you often see this kind of sentences in your English study?
A. always
B. sometimes
C. unclear
D. seldom
E. never

( ) 2. Do you feel it difficult to translate these sentences?
A. very much
B. a little
C. so-so
D. easy
E. very easy

( ) 3. Did your English teacher pay attention to such sentences in teaching?
A. very much
B. comparatively
C. sometimes
D. average
E. never

( ) 4. Are you sure of the objects of negation in the sentences?
A. completely
B. comparatively
C. not completely
D. unsure
E.very unsure

( ) 5 . Will you think about the objects of negation before you translate such sentences?
A. completely
B. comparatively
C. not completely
D. unsure
E. very unsure 
( ) 6. How many negation structures in these sentences do you think is the same as that of Chinese?
A. none
B. $1-5$
C. 6-10
D. 11-15
E. over 15

( ) 7. Will you be influenced by the habit of Chinese expression when interpreting the sentences?
A. very much
B. to some degree
C. unclear
D. seldom
E. never

( ) 8 . How often do you use transferred negation structure when writing a composition?
A. always
B. sometimes
C. unclear
D. seldom
E. never

( ) 9 . What is your difficulty when translating these sentences?
A. new/complicated words
B. unfamiliar/complicated sentence structure
C. negation structure in sentences

( ) 10. What do your think is the key point when translating these sentences?
A. new words
B. sentence structure
C. negation structure in sentences

\section{Copyrights}

Copyright for this article is retained by the author(s), with first publication rights granted to the journal.

This is an open-access article distributed under the terms and conditions of the Creative Commons Attribution license (http://creativecommons.org/licenses/by/3.0/). 